\title{
Retrospective study of juvenile systemic lupus erythematosus (JSLE) over the last 20 years: single center experience
} L Tambic Bukovac, M Jelusic*, D Batinic, M Vidovic, D Milosevic, K Vrljicak and Lj Nizic

Address: Department of Paediatrics, University Hospital Centre, Zagreb University School of Medicine, Zagreb, Croatia

* Corresponding author

from $15^{\text {th }}$ Paediatric Rheumatology European Society (PreS) Congress

London, UK. 14-17 September 2008

Published: 15 September 2008

Pediatric Rheumatology 2008, 6(Suppl I):P243 doi:10.I I86/I546-0096-6-SI-P243

This abstract is available from: http://www.ped-rheum.com/content/6/SI/P243

(c) 2008 Tambic Bukovac et al; licensee BioMed Central Ltd.

\section{Introduction}

Children represent approximately $15-20 \%$ of all systemic lupus erythematosus (SLE) patients, and they usually have a more severe disease at onset, higher rates of organ involvement, and a more aggressive clinical course than adults.

\section{Aim}

To analyze characteristics of the presenting and cumulative clinical features, immunologic manifestations, disease activity and outcome of 62 Croatian children with JSLE, followed between 1987 and 2007.

\section{Results}

There were 62 children, 52 girls and 10 boys, with the mean age at disease onset $( \pm$ SD) $12.9 \pm 2.4$ years. Fiftyeight patients were followed for a mean period of $6.9 \pm 5.3$ yrs. The commonest presenting clinical features were constitutional (fever, fatigue) (68\%), arthralgias (56\%), renal involvement (53\%) and malar rash (29\%). Renal biopsy revealed class IV lupus nephritis (LN) in 15 (45,5\%), class III LN in $9(27,3 \%)$, class II LN in $5(15,1 \%)$ and class V LN in $4(12,1 \%)$ cases. The patients presented significantly altered laboratory parameters including deficiency of complement C3 (93\%) and C4 (95\%), high ESR (95\%), cytopenia (73\%) and positive anti-dsDNA (100\%). Only two patients had severe opportunistic infections: CNS nocardiosis and multifocal staphylococcal osteomyelitis, both with good outcome. Due to clinical presentation and laboratory data most patients were treated with oral corticosteroids, followed by cyclophosphamide, pulse steroid, hydroxychloroquine and azathioprine. During the study period two patients died, one because catastrophic antiphospholid syndrome, other because of terminal renal failure.

\section{Conclusion}

There is no significant difference in clinical, immunopathological features and therapy regimens in our patients compared to those in most paediatric SLE studies. 